\title{
EFICIÊNCIA DOS ÓLEOS DE NIM E MAMONA CONTRA CUPINS XILÓFAGOS EM ENSAIO DE ALIMENTAÇÃO FORÇADA
}

\author{
Juarez Benigno Paes ${ }^{1}$, Ademilson Daniel de Souza ${ }^{2}$, Carlos Roberto de Lima ${ }^{3}$, Pedro Nicó de Medeiros Neto ${ }^{4}$
}

(recebido: 23 de julho de 2009; aceito: 29 de janeiro de 2010)

\begin{abstract}
RESUMO: Conduziu-se esta pesquisa com o objetivo de avaliar a eficiência dos óleos de nim (Azadirachta indica) e de mamona (Ricinus communis) na resistência da madeira de sumaúma (Ceiba pentandra) ao térmita xilófago Nasutitermes corniger em ensaio de alimentação forçada. Os óleos das sementes de nim e de mamona foram extraídos com álcool etílico absoluto e empregados no preparo das soluções preservantes. Amostras de madeira com dimensões de 2,0 x 2,54 x 0,64 cm (radial x longitudinal x tangencial) foram tratadas para atingir uma retenção nominal de 10 a $16 \mathrm{~kg}$ de solução $/ \mathrm{m}^{3}$ de madeira. Parte das amostras tratadas foi submetida ao envelhecimento (volatilização ou lixiviação). As amostras tratadas foram submetidas à ação de cupins em ensaios de alimentação forçada. Os óleos de nim e de mamona, na retenção empregada, não contribuíram para a melhoria da resistência da madeira de sumaúma ao ataque de cupins e entre as soluções testadas, o óleo de mamona puro foi mais eficiente. O envelhecimento das amostras não influenciou a resistência da madeira. Os óleos de nim e de mamona puros e suas soluções, mesmo apresentando algum efeito de repelência aos cupins, não têm efeito duradouro, indicando que os mesmos não são eficientes no tratamento da madeira contra cupins xilófagos.
\end{abstract}

Palavras-chave: Óleos de nim e mamona, tratamento da madeira, envelhecimento, térmitas xilófagos.

\section{EFFICIENCY OF NEEM AND CASTOR OIL PLANT OILS AGAINST XILOPHOGOUS TERMITES UNDER FORCED FOOD ASSAY}

\begin{abstract}
The research aimed to evaluate the efficiency of neem (Azadirachta indica) and castor oil plant (Ricinus communis) oils to improvement of Ceiba pentandra wood resistance to Nasutitermes corniger xilophogous termite under forced food assay. The neem and castor oil plant oils were extracted with absolute ethyl alcohol and employees in the preparation of oil solutions. Wood samples with dimensions of $2.0 \times 2.54 \times 0.64 \mathrm{~cm}$ (radial $\times$ longitudinal $\times$ tangential) were treated to reach a nominal retention of 10 to $16 \mathrm{~kg}$ of solution $/ \mathrm{m}^{3}$ of wood. A part of treated samples was submitted to the weathering test (volatily and leaching tests). The treated samples were submitted to termite action under forced food assay. The neem and castor oil plant oils, on employed retention, did not contribute to improvement of Ceiba pentandra wood resistance to xylophogous termites. Among the tested solutions, the pure castor oil plant oil was more efficient. The weathering test of samples did not influence the wood resistance. The neem and of pure castor oil plant oils and their solutions, even presenting some repulsive effect to termites, their effect are not durable, indicating that they should not be used in wood treatment in order to improve its resistance to xylophogous termites.
\end{abstract}

Key words: Neem, castor oil plant oils, wood treatment, weathering, xylophogous termites.

\section{INTRODUÇÃO}

O nim (Azadirachta indica A. Juss) é uma planta da família Meliaceae, de origem asiática, muito resistente e de rápido crescimento, alcançando normalmente de 10 a $15 \mathrm{~m}$ de altura (ARAUJO et al., 2000). Sua madeira é dura, relativamente pesada e utilizada na confecção de casas, móveis, carretas, ferramentas, implementos agrícolas e moirões de cerca (PLANETANATURAL, 2006), em razão de sua resistência ao ataque de cupins e ao apodrecimento (PAES et al., 2007; PLANETANATURAL, 2006). É uma excelente fonte de lenha e combustíveis, possuindo um carvão de alto poder calorífico (ARAÚJO et al., 2000). Além de boa fonte energética, o nim indiano também é recomendado no manejo de pragas.

Os frutos, sementes, óleo, folhas, cascas do caule e raízes do nim possuem os mais variados usos antissépticos e antimicrobianos. O óleo e seus componentes afugentam

\footnotetext{
${ }^{1}$ Engenheiro Florestal, Professor D.Sc. - Departamento de Engenharia Florestal - Universidade Federal do Espírito Santo - Av. Governador Lindemberg, 316, Centro - 29550-000 - Jerônimo Monteiro, ES - jbp2@uol.com.br

${ }^{2}$ Engenheiro Florestal - Unidade Acadêmica de Engenharia Florestal - Universidade Federal de Campina Grande - Cx. P. 64 - $58700-970$ Patos, PB - dsouzaig@gmail.com

${ }^{3}$ Engenheiro Florestal, Professor M.Sc. - Unidade Acadêmica de Engenharia Florestal - Universidade Federal de Campina Grande Cx. P. 64 - 58700-970 - Patos, PB - crlima16@ hotmail.com

${ }^{4}$ Engenheiro Florestal, Mestrando do Programa de Pós-Graduação em Ciências Florestais - Unidade Acadêmica de Engenharia Florestal Universidade Federal de Campina Grande - Cx. P. 64 - 58700-970 - Patos, PB - pedroflorestal@gmail.com
} 
insetos e inibem o desenvolvimento de fungos sobre homens, animais e plantas. Porém, após vinte dias em contato com o solo, o óleo se deteriora (PLANETANATURAL, 2006), dificultando seu emprego para o tratamento de madeira, em que os princípios ativos das substâncias empregadas para esta finalidade, devem persistir por longo tempo nas peças tratadas.

A mamona (Ricinus communis L) é uma planta oleaginosa, pertencente à família Euforbiaceae, originária da África que chegou ao Brasil no período Colonial (VENTURA, 1990). Por causa de suas características de rusticidade e adaptabilidade tem sido estudada e explorada, para atender aos programas de produção de biocombustível e para fixar o homem no campo, principalmente no Semiárido brasileiro (MACHADO et al., 1998).

Para determinados fins, o óleo de mamona, é quase insubstituível, sendo indicado para lubrificação de engrenagens sujeitas ao esfriamento e à ação da água, por aderir bem às superfícies molhadas, ao contrário dos demais óleos (MACHADO et al., 1998). Desta forma, espera-se que o óleo de mamona possa melhorar a persistência do óleo de nim na madeira.

A sumaúma (Ceiba pentandra (L) Gaerth.), família Bombacaceae, é mundialmente conhecida por suas múltiplas utilidades. É uma espécie característica de florestas abertas, atingindo de 30 a $40 \mathrm{~m}$ de altura. Produz madeira leve $\left(0,30\right.$ a $\left.0,37 \mathrm{~g} / \mathrm{cm}^{3}\right)$, de cor esbranquiçada quando recém cortada que, posteriormente, muda para castanho ou cinza (LOUREIRO et al., 1979), possui grã regular, textura média, cheiro e gosto indistinto, sendo suscetível ao ataque de insetos e fungos apodrecedores (SOUZA et al., 1997).

Em razão de suas características físico-mecânicas, da disponibilidade e da trabalhabilidade, a madeira de sumaúma (Ceiba pentandra) é muito empregada em várias regiões do Brasil para a confecção de compensados, móveis, batentes de portas e janelas e mais em uma infinidade de usos.

Os térmitas (cupins) são, dentre os insetos, os mais severos agentes destruidores da madeira (PAES \& VITAL, 2000). Dentre os cupins, os de solos ou subterrâneos são responsáveis pelos maiores volumes de perdas de madeira no mundo (HUNT \& GARRATT, 1967; RICHARDSON, 1993).

No Semiárido brasileiro, cupins da espécie Nasutiterme corniger (Motsch.), família Termitidae, são capazes de invadir, com sucesso, o meio urbano, atacando móveis e outros objetos construídos com madeira, como batentes de portas e janelas e, principalmente, madeiras empregadas nas estruturas das construções (PAES et al., 2001).

São executados em laboratório dois tipos de ensaios para testar a resistência da madeira e de produtos lignocelulósicos a cupins subterrâneos: o ensaio normatizado pela American Society for Testing and Materials - ASTM (2005b) D - 3345 e pela Associação Francesa de Normalização (AFNOR - NFX - 41-539), citada por Lepage et al. (1986), conhecidos por ensaio de alimentação forçada e o proposto por Supriana (1985) denominado de ensaio de preferência alimentar.

No ensaio de alimentação forçada, os cupins subterrâneos são mantidos em recipientes contendo areia, onde pequenos blocos de madeira são expostos à população, de tamanho pré-determinado, por um período de quatro semanas. Ao término do ensaio, os corpos-deprova devem ser examinados e o ataque avaliado com base em um critério subjetivo, que envolve a atribuição de notas e da porcentagem de mortalidade (ASTM, 2005b). Conforme a Associação Francesa de Normalização (AFNOR - NFX 41-539), citada por Lepage et al. (1986), a avaliação do ensaio deve envolver também a porcentagem da perda de massa da madeira. Além desses parâmetros, Jankowsky (1986) e Paes (1997) citam que o número de dias para a morte dos cupins é considerado um bom indicativo da eficiência de produtos preservativos para proteger a madeira. Pois, quando os cupins morrem rapidamente, significa que a substância química foi letal aos insetos (PAES et al., 2003).

Assim, esta pesquisa teve como objetivos avaliar o efeito dos óleos de nim (Azadirachta indica) e de mamona (Ricinus communis) na resistência da madeira de sumaúma (Ceiba pentandra) ao térmita xilófago Nasutitermes corniger em ensaio de alimentação forçada.

\section{MATERIAL E MÉTODOS}

\subsection{Coleta e beneficiamento dos frutos de nim e de mamona}

Os frutos de nim (Azadirachta indica A. Juss) foram coletados no Núcleo de Pesquisa do Semiárido (NUPEARIDO), pertencente à Universidade Federal de Campina Grande (UFCG), localizado no Município de Patos, PB. Já, os frutos de mamona (Ricinus communis L) foram coletados de várias plantas que crescem as margens do Rio Espinharas (Patos, PB), e no Município de Igaracy, PB. 
Após a coleta, os frutos de nim foram armazenados em geladeira, e quando a quantidade coletada foi suficiente para a extração dos óleos, eles foram despolpados em água corrente com auxílio de uma peneira de malha de $2 \times 3 \mathrm{~mm}$, secos à sombra no Laboratório de Tecnologia de Produtos Florestais (LTPF) da Unidade Acadêmica de Engenharia Florestal (UAEF) do Centro de Saúde e Tecnologia Rural (CSTR) da UFCG, e retirado o tegumento com ferramentas manuais e armazenados à sombra no LTPF.

Os frutos de mamona foram postos ao sol para eclodirem e as sementes armazenadas em sacos plásticos no LTPF, até o encaminhamento para as extrações de óleos.

\subsection{Preparo das soluções com os óleos de nim e mamona}

Para a extração dos óleos foi empregado álcool etílico absoluto. As sementes depois de moídas em moinho manual foram misturadas ao álcool e, posteriormente, homogeneizadas com o uso de liquidificador doméstico. O material obtido foi posto em um funil de Büchner de 13 $\mathrm{cm}$ de diâmetro por $4 \mathrm{~cm}$ de altura e filtrado com papel de filtro de filtragem rápida ao empregar uma bomba de vácuo acoplada a um erlenmeyer de $2000 \mathrm{~mL}$.

Para o óleo de nim, após a filtragem, observaram-se duas camadas (óleo e solvente), que foram separadas naturalmente com o emprego de um funil de decantação de $500 \mathrm{~mL}$. O óleo de mamona ficou miscível no álcool, tendo sido separado por aquecimento e condensação do solvente, ao empregar um balão de $1000 \mathrm{~mL}$, manta aquecedora e um condensador tipo Liebig de $40 \mathrm{~cm}$ de comprimento, tendo a fração alcoólica sido recuperada e reutilizada.

Depois de tais procedimentos, os óleos foram postos em bandejas de alumínio, cobertas com tecido tipo filó e dispostas no laboratório para a evaporação das porções remanescentes de álcool.
Para atender aos objetivos do trabalho foram preparadas cinco soluções com os óleos obtidos de nim e mamona. No preparo, foram variadas as quantidade de óleo de nim e de mamona (Tabela 1).

\subsection{Preparo e tratamento da madeira de sumaúma}

A madeira de sumaúma (Ceiba pentandra (L.) Gaerth.) foi obtida em uma marcenaria localizada no município de Patos - PB, com dimensões de $3,5 \mathrm{~cm}$ de espessura, $30 \mathrm{~cm}$ de largura e 200 centímetros de comprimento. A madeira foi transformada em corpos-deprova, de 2,0 x 2,54 x 0,64 $\mathrm{cm}$ de dimensões (radial x longitudinal $\mathrm{x}$ tangencial).

As amostras obtidas foram selecionadas ao descartar aquelas que apresentavam defeitos, lixadas e identificadas convenientemente em função do tratamento a ser empregado (Tabela 1), do teste biológico e das condições do teste.

Os corpos-de-prova selecionados foram secos em estufa a $103 \pm 2{ }^{\circ} \mathrm{C}$, até massa constante. Foram determinadas a massa e o volume de cada amostra, conforme o recomendado pela ASTM (2005a) e os valores utilizados no cálculo da densidade da madeira, da retenção dos óleos na madeira e da perda de massa causada pelos cupins xilófagos.

Para o tratamento da madeira, foi empregado o método de imersão a frio em que as amostras de madeira foram submergidas por 5 minutos nas soluções preparadas, conforme Tabela 1. Com esse procedimento garantiram-se retenções de 10 a $16 \mathrm{~kg}$ de solução $/ \mathrm{m}^{3}$ de madeira. O nível de retenção empregado teve como base o utilizado por Fonsêca (2008) para o óleo de candeia (Eremanthus erythropappus), o qual garantiu que amostras de sumaúma tratadas apresentassem alta resistência ao ataque de cupins da espécie Nasutitermes corniger.

Tabela 1 - Soluções preparadas com os óleos de nim (Azadirachta indica) e mamona (Ricinus communis) e tratamentos a serem executados na madeira de sumaúma (Ceiba pentandra).

Table 1 - Solutions prepared with neem (Azadirachta indica) and castor oil plant (Ricinus communis) oils and treatments to be executed in Ceiba pentandra wood.

\begin{tabular}{cc}
\hline Tratamentos Estatísticos & Discriminações \\
\hline 1 & Testemunha (madeira sem tratamento) \\
2 & Óleo de nim puro \\
3 & $25 \%$ de mamona e $75 \%$ de nim \\
4 & $50 \%$ de mamona e $50 \%$ de nim \\
6 & $75 \%$ de mamona e $25 \%$ de nim \\
\hline
\end{tabular}


Após o tratamento, os corpos-de-prova foram submetidos a três situações distintas. No primeiro caso, as amostras tratadas tiveram suas superfícies secas com papel toalha, determinada sua retenção e, em seguida, submetidas ao ensaio biológico. Essa foi denominada de situação normal (situação 1). No segundo caso, os corpos-de-prova, após secos, foram submetidos ao envelhecimento por volatilização, segundo recomendações da norma ASTM D1413 (ASTM, 2005a), que preconiza a imersão das amostras em água destilada por 2 horas, à temperatura ambiente, seguida da secagem em estufa a $48,9 \pm 1,1^{\circ} \mathrm{C}$, por 334 horas. Após esse tratamento, as amostras foram submetidas ao ensaio (situação 2). No terceiro caso, os corpos-de-prova, após secos, foram submetidos à lixiviação, segundo recomendações do IPT/DIMAD, citadas por Paes (1997), as quais preconizam a imersão das amostras num recipiente, onde são reguladas a entrada e a saída de água para $400 \mathrm{~mL} / \mathrm{min}$, por 150 horas. Em seguida, as amostras foram acondicionadas em condições ambientais, por 15 dias, e submetidas ao ensaio (situação 3).

\subsection{Ensaio de resistência a cupins subterrâneos}

Para realização do ensaio de alimentação forçada, foram seguidas as recomendações da norma ASTM D3345 (ASMT, 2005b), com algumas modificações sugeridas por Paes (1997). Assim, foram ensaiadas sete amostras para cada tratamento (solução/situação). As amostras foram tratadas conforme descrito no item 2.3 e a retenção (kg de substância preservativa $/ \mathrm{m}^{3}$ de madeira) determinada ao dividir a diferença de massa dos corpos-de-prova (antes e depois de tratados) pelo volume inicial dos mesmos.
Segundo as recomendações da norma citada, o ensaio foi montado em frascos preenchidos com $200 \mathrm{~g}$ de areia, tendo sua umidade sido corrigida para $75 \%$ de sua capacidade de retenção, pela adição de $32 \mathrm{~mL}$ de água destilada. Em cada frasco, foram adicionados um corpo-de-prova e $1 \pm 0,05 \mathrm{~g}$ de cupins subterrâneos da espécie Nasutitermes corniger, equivalente a \pm 390 indivíduos, aproximadamente, $80 \%$ de operários (proporção existente na colônia).

Após a adição dos cupins, os frascos foram tampados, frouxamente, a fim de permitir a circulação de ar. Assim procedendo, foram montadas sete repetições para cada tratamento e situação. As amostras permaneceram em sala climatizada $\left(28 \pm 2^{\circ} \mathrm{C}\right.$ e $75 \pm 5 \%$ de umidade relativa), por 28 dias.

Para avaliar a eficiência das soluções preservativas empregadas, foram computados a perda de massa, o número de indivíduos mortos, a porcentagem de mortalidade, o tempo em dias, para ocorrer a mortalidade, e o desgaste produzido na madeira. A perda de massa foi corrigida por meio de amostras tratadas, submetidas às mesmas condições de ensaio, porém sem a presença de cupins (perda de massa operacional). $\mathrm{O}$ desgaste e a mortalidade foram avaliados conforme descrito na Tabela 2 .

\subsection{Avaliação dos resultados}

Para avaliação dos resultados, foi empregado o delineamento inteiramente casualisado e os dados em porcentagens de perda de massa e de mortalidade foram transformados em arcsen [raiz quadrada (perda de massa ou mortalidade $\div 100$ )] e os de desgaste (nota) e tempo (dias) para a morte dos cupins em raiz quadrada (nota ou dias $+0,5$ ).

Tabela 2 - Avaliação do desgaste provocado nos corpos-de-prova e mortalidade dos cupins (ASTM, 2005b).

Table 2 - Evaluation of waste caused in test samples and mortality of termites (ASTM, 2005b).

\begin{tabular}{lc}
\hline Tipo de Desgaste & Nota \\
\hline Sadio, permitindo escarificações superficias & 10 \\
Ataque superficial & 9 \\
Ataque moderado, havendo penetração & 7 \\
Ataque intenso & 4 \\
Falha, havendo ruptura dos corpos-de-prova & 0 \\
\hline Mortalidade & $(\%)$ \\
\hline Baixa & $0-33$ \\
Moderada & $34-66$ \\
Alta & $67-99$ \\
Total & 100 \\
\hline
\end{tabular}

Cerne, Lavras, v. 16, n. 1, p. 105-113, jan./mar. 2010 
Essas transformações, sugeridas por Steell \& Torrie (1980), foram necessárias para homogeneizarem as variâncias e permitirem sua análise. Para a avaliação dos ensaios foi empregado o teste de Tukey em nível de 5\% de probabilidade.

A análise estatística dos dados foi processada por meio do Sistema de Análises Estatísticas e Genéticas (SAEG), desenvolvido pela Central de Processamento de Dados (CPD) da Universidade Federal de Viçosa (UFV), para analisar a eficiência do óleo de nim e de mamona em função dos tratamentos e situações empregados.

\section{RESULTADOS E DISCUSSÃO}

Ao analisar os dados apresentados na Tabela 3, nota-se que os tratamentos 5 ( $75 \%$ de óleo de mamona e $25 \%$ de óleo de nim) e 6 (óleo de mamona puro) das situações 1(normal) e 3 (lixiviada) apresentaram menores valores de perda de massa, em relação aos demais tratamentos. Isso indica que os tratamentos com maiores proporções de óleo de mamona foram aqueles que apresentaram maior eficiência contra o ataque de cupins, pois mesmo nos corpos-de-prova submetidos à lixiviação, o óleo persistiu na madeira, conferindo, assim, maior resistência ao ataque.

Para a situação 2 (volatilizada), os tratamentos 2 (óleo de nim puro) e 6 apresentaram os menores valores de perda de massa, indicando que tanto os óleos de nim quanto os de mamona puros, quando submetidos a volatilização, apresentaram maior eficiência na madeira que as soluções preparadas com os mesmos.

Com relação à mortalidade dos cupins, com base na Tabela 2, verificou-se que foi alta para a maioria dos tratamentos, com exceção dos tratamentos 3 (25\% de mamona e 75\% de nim) e 4 (50\% de cada óleo) da situação 1(normal), que foi moderada. Quanto ao número de dias para morte dos cupins, observa-se que o tratamento 6 (situação 1) foi o que apresentou menor tempo (dias), para a morte dos térmitas. No entanto, para a situação 2, os menores valores foram observados nos tratamentos 1 (testemunha) e 3 ( $25 \%$ mamona e $75 \%$ nim), demonstrando que, mesmo nas amostras não-tratadas (testemunhas, tratamento 1), os cupins morreram rápido. Já, para a situação 3, os tratamentos que apresentaram os menores valores foram o 1 e 6 , demonstrando que nenhuma das soluções de tratamento empregadas apresentou eficiência contra os térmitas no ensaios de alimentação forçada.

Com relação ao desgaste (nota) causado pelos cupins, observou-se que os tratamentos 2, 3 e 4 foram aqueles que apresentaram os menores valores (situações
1 e 3). Esse comportamento foi semelhante ao observado para os valores de perda de massa (\%), demonstrando que as avaliações subjetivas (notas) foram bem executadas.

A madeira de Pinus sp., utilizada como padrão de comparação (ASTM, 2005b) sofreu perda de massa de 4,54 \%; desgaste (nota) de 7,0; e mortalidade de $100 \%$ aos 15 dias de ensaio, indicando que os cupins empregados não tinham hábito de se alimentarem da madeira de Pinus sp., uma vez que os mesmos eram provenientes de colônias instaladas em uma árvore de Cassia grandis, da utilização da madeira de sumaúma em várias instalações e do pouco uso da madeira de Pinus sp. na região. Supriana (1985) afirma que os cupins são muito seletivos na sua dieta, não atacando espécies com as quais têm pouco contato. Observação semelhante foi relatada por Paes et al. (1998).

O resumo das análises de variância (Tabela 4) indica que houve diferença significativa pelo teste $\mathrm{F}$ a $1 \%$ de probabilidade entre os tratamentos, para todos os parâmetros analisados. Entre as situações, a diferença foi significativa a $5 \%$ de probabilidade para a perda de massa e a $1 \%$, para o desgaste, mortalidade e tempo para morte dos cupins. Para a interação, houve efeito significativo a $5 \%$ de probabilidade para a mortalidade e a $1 \%$ para o tempo (dias) para a morte dos cupins. Os valores dos parâmetros e das interações, quando significativas, foram analisados pelo teste de Tukey a $5 \%$ de probabilidade (Tabela 5).

Observa-se (Tabela 5) que os tratamentos que proporcionaram menores valores de perda de massa foram o 6 e 5 . Os tratamentos 1, 2, 3 e 4 foram semelhantes em si e não diferiram do tratamento 5. Já para o desgaste, notas menores indicam maiores ataques na madeira, o que condiz, de modo geral, com os valores de perda de massa.

Para as situações em que as amostras foram submetidas, a situação 1 (normal) foi a que apresentou maior valor de perda de massa quando comparado com as situações 2 e 3. Comportamento inverso ocorreu para o desgaste (nota), em que a situação 1 apresentou valor inferior ao das demais.

Os valores de mortalidade e tempo (dias) para a morte dos cupins encontram-se na Tabela 6. Nesses casos, a interação (tratamento e situação) foi desdobrada e analisada. A análise da mortalidade dos cupins indicou que para os tratamentos 1 e 6 , nas situações 1,2 e 3 apresentaram comportamento semelhante. Para os tratamento 3 e 4 a situação 1 apresentou uma mortalidade inferior às das demais situações. No entanto, para o tratamento 2, a situação 2 (volatilizada) apresentou uma maior mortalidade e a 1 (normal) a menor, tendo a situação 3 (lixiviada) um

Cerne, Lavras, v. 16, n. 1, p. 105-113, jan./mar. 2010 
Tabela 3 - Valores médios da perda de massa (\%), mortalidade (\%), tempo (dias) e desgaste (nota), dos corpos-de-provas submetidos aos cupins.

Table 3 - Medium values of loss of mass (\%), mortality (\%), time (days) and waste (note), of test samples submitted to termites.

\begin{tabular}{|c|c|c|c|c|c|}
\hline Situação & Tratamento & Perda de Massa (\%) & Mortalidade (\%) & Tempo (dias) & Desgaste (nota) \\
\hline \multirow{6}{*}{1 (Normal) } & 1 & 13,15 & 91,0 & 24 & 6,97 \\
\hline & 2 & 12,07 & 71,4 & 27 & 5,40 \\
\hline & 3 & 12,71 & 65,6 & 26 & 5,82 \\
\hline & 4 & 12,17 & 55,0 & 28 & 5,11 \\
\hline & 5 & 8,23 & 77,7 & 26 & 6,77 \\
\hline & 6 & 5,23 & 92,7 & 17 & 8,57 \\
\hline \multirow{6}{*}{2 (Volatilizada) } & 1 & 8,69 & 100 & 12 & 8,85 \\
\hline & 2 & 7,89 & 100 & 17 & 8,25 \\
\hline & 3 & 8,35 & 100 & 14 & 8,14 \\
\hline & 4 & 9,65 & 88 & 19 & 7,34 \\
\hline & 5 & 9,15 & 90,3 & 20 & 7,31 \\
\hline & 6 & 7,23 & 100 & 17 & 7,74 \\
\hline \multirow{6}{*}{3 (Lixiviada) } & 1 & 10,42 & 100 & 16 & 7,85 \\
\hline & 2 & 9,57 & 88,57 & 22 & 6,74 \\
\hline & 3 & 10,7 & 85,42 & 24 & 6,43 \\
\hline & 4 & 8,42 & 94,57 & 21 & 6,71 \\
\hline & 5 & 7,98 & 100 & 18 & 7,54 \\
\hline & 6 & 6,39 & 100 & 17 & 8,28 \\
\hline
\end{tabular}

Tabela 4 - Resumo das análises de variância para os valores de perda de massa, desgaste, mortalidade e tempo (dias) para morte dos cupins submetidos aos ensaios. Valores transformados em arcsen [raiz quadrada (x/100)] (perda de massa e mortalidade) ou raiz quadrada $(\mathrm{x}+0,5)$ (desgaste e tempo).

Table 4 - Summary of variance analyzes to loss of mass, waste, mortality and time (days) values to death of termites submitted to assays. Values transformed in arcsine [square rote $(x / 100)$ ] (loss of mass and mortality) or square rot $(x+0.5)($ waste and time).

\begin{tabular}{lccccc}
\hline \multirow{2}{*}{ Fonte de Variação } & Graus de Liberdade & \multicolumn{4}{c}{ Quadrados Medios } \\
\cline { 3 - 6 } & & Perda de Massa $(\%)$ & Desgaste (Nota) & Mortalidade (\%) & Tempo (dias) \\
\hline Tratamento & 5 & $0,21 \times 10^{-1} * *$ & $0,36 * *$ & $0,27 * *$ & $1,52 * *$ \\
Situação & 2 & $0,10 \times 10^{-1} *$ & $0,99 * *$ & $1,85 * *$ & $8,31 * *$ \\
Trat. x Sit. & 10 & $0,53 \times 10^{-2} \mathrm{NS}$ & $0,13^{\mathrm{NS}}$ & $0,11^{*}$ & $0,73 * *$ \\
Resíduo & 108 & $0,29 \times 10^{-2}$ & $0,89 \times 10^{-1}$ & $0,55 \times 10^{-1}$ & 0,26 \\
\hline \multicolumn{1}{c}{ Coeficiente de Variação $(\%)$} & 17,68 & 10,86 & 17,02 & 11,17 \\
\hline
\end{tabular}

** Significativo a $1 \%(\mathrm{p}<0,01)$; * Significativo a $5 \%(0,01<\mathrm{p} \leq 0,05) ;{ }^{\text {NS }}$ não significativo a $5 \%(\mathrm{p}>0,05)$ pelo teste de $\mathrm{F}$.

comportamento intermediário, não diferindo das situações 1 e 2. Comportamento semelhante foi observado para o tratamento 5, em que a situação 1 apresentou a menor mortalidade e a 3 a maior, tendo a situação 2, apresentado resultado intermediário entre as situações 1 e 3.
A análise do tratamento em cada situação, indicou que para a situação 1 (normal), o tratamento 6 (óleo de mamona puro) apresentou uma maior mortalidade que o tratamento 4 (50\% óleo de nim e $50 \%$ óleo de mamona), tendo os demais tratamentos apresentado efeito

Cerne, Lavras, v. 16, n. 1, p. 105-113, jan./mar. 2010 
Tabela 5 - Comparações entre médias para a perda de massa (\%) e desgaste (nota) dos corpos-prova submetidos ao ensaio de alimentação forçada, para cada situação e tratamento analisados.

Table 5 - Comparison among averages to loss of mass (\%) and waste (note) of test samples submitted to forced food assay, to each analyzed situation and treatment.

\begin{tabular}{ccc}
\hline Tratamentos & Perda de massa (\%) & Desgaste (nota) \\
\cline { 2 - 3 } & Medias verdadeiras & Medias verdadeiras \\
\hline 1 & $10,75 \mathrm{a}$ & $7,76 \mathrm{ab}$ \\
3 & $9,84 \mathrm{a}$ & $6,80 \mathrm{abc}$ \\
4 & $10,68 \mathrm{a}$ & $6,80 \mathrm{bc}$ \\
5 & $10,08 \mathrm{a}$ & $6,39 \mathrm{c}$ \\
6 & $8,45 \mathrm{ab}$ & $7,21 \mathrm{abc}$ \\
\hline Situação & $6,28 \mathrm{~b}$ & $8,20 \mathrm{a}$ \\
\hline 1 (Normal) & Perda de massa (\%) & Desgaste (nota) \\
2 (Volatilizada) & Medias verdadeiras & $6,37 \mathrm{~b}$ \\
3 (Lixiviada) & $10,59 \mathrm{a}$ & $7,94 \mathrm{a}$ \\
\hline
\end{tabular}

As médias seguidas por uma mesma letra, em cada seção, não diferem entre si (Tukey; $p \geq 0,05$ ).

Tabela 6 - Comparações entre médias para a mortalidade (\%) e tempo (dias) dos cupins submetidos ao ensaio de alimentação forçada, para cada situação e tratamento analisados.

Table 6 - Comparison among averages to mortality (\%) and time (days) of termites submitted to forced food assay, to each analyzed situation and treatment.

\begin{tabular}{|c|c|c|c|}
\hline \multicolumn{4}{|c|}{ Mortalidade dos cupins (\%) } \\
\hline \multirow{2}{*}{ Tratamento } & \multicolumn{3}{|c|}{ Situação } \\
\hline & 1 & 2 & 3 \\
\hline 1 & $86,00 \mathrm{Aab}$ & $100,00 \mathrm{Aa}$ & $100,00 \mathrm{Aa}$ \\
\hline 2 & $71,43 \mathrm{Bbc}$ & $100,00 \mathrm{Aa}$ & $88,57 \mathrm{ABa}$ \\
\hline 3 & $65,57 \mathrm{Bbc}$ & $100,00 \mathrm{Aa}$ & $85,42 \mathrm{Aa}$ \\
\hline 4 & $55,00 \mathrm{Bc}$ & $88,00 \mathrm{Aa}$ & $94,57 \mathrm{Aa}$ \\
\hline 5 & 77,71 Babc & $90,28 \mathrm{ABa}$ & $100,00 \mathrm{Aa}$ \\
\hline 6 & $92,71 \mathrm{Aa}$ & $100,00 \mathrm{Aa}$ & $100,00 \mathrm{Aa}$ \\
\hline \multicolumn{4}{|c|}{ Tempo (dias) para morte dos cupins } \\
\hline \multirow{2}{*}{ Tratamento } & \multicolumn{3}{|c|}{ Situação } \\
\hline & 1 & 2 & 3 \\
\hline 1 & $24,43 \mathrm{Aa}$ & $12,57 \mathrm{Bb}$ & $16,14 \mathrm{Bb}$ \\
\hline 2 & $27,00 \mathrm{Aa}$ & $17,85 \mathrm{Bab}$ & $22,71 \mathrm{ABab}$ \\
\hline 3 & $26,71 \mathrm{Aa}$ & $14,87 \mathrm{Bab}$ & $24,57 \mathrm{Aa}$ \\
\hline 4 & $28,00 \mathrm{Aa}$ & $19,00 \mathrm{Bab}$ & $21,28 \mathrm{Bab}$ \\
\hline 5 & $26,71 \mathrm{Aa}$ & $20,43 \mathrm{Ba}$ & $18,71 \mathrm{Bab}$ \\
\hline 6 & $17,28 \mathrm{Ab}$ & $17,43 \mathrm{Aab}$ & $17,57 \mathrm{Aab}$ \\
\hline
\end{tabular}

As médias seguidas por uma mesma letra maiúscula, na horizontal ou minúscula, na vertical, em cada seção, não diferem entre si (Tukey; $\mathrm{p} \geq 0,05$ ). 
intermediário com relação à mortalidade dos cupins. No entanto, para as situações 2 e 3 (volatilizada e lixiviada), todos os tratamentos apresentaram efeito semelhante na mortalidade dos cupins.

Com relação ao número de dias para a morte dos cupins, o tratamento 6 proporcionou efeito semelhante para todas as situações. No entanto, nos tratamentos 1 , 4 e 5 , as situações 2 e 3 apresentaram um menor tempo para a morte dos cupins, quando comparadas a situação 1 . Para os tratamento 2 e 3 , as amostras submetidas à situação 2 apresentaram o menor tempo para a morte dos cupins.

Para a situação 1 (normal), o tratamento 6 foi o mais eficiente por apresentar menor tempo para a morte dos cupins (JANKOWSKY, 1986; PAES, 1997). No entanto, para a situação 2 (volatilizada), o tratamento 1 apresentou o menor tempo para a morte dos térmitas e o tratamento 5 foi o menos eficiente, tendo, os demais, apresentado eficiência intermediária. Para a situação 3 (lixiviada), o tratamento 3 foi o menos eficiente, e o tratamento 1 foi aquele que os insetos permaneceram vivos por menos tempos, tendo os demais tratamentos proporcionado comportamento intermediário entre os tratamentos 1 e 3 .

Esperava-se que as amostras submetidas às situações 2 (volatilizada) e 3 (lixiviada), a exemplo do observado por Paes (1997), não apresentassem efeito quanto à mortalidade dos cupins, ou que apresentassem comportamento inferior ao da situação 1 (normal), em que as amostras não foram submetidas a nenhum tratamento que simulasse o envelhecimento da madeira tratada.

A mortalidade dos cupins pode ter sido influenciada pelas condições do meio. Uma vez que os cupins subterrâneos são muito sensíveis às alterações de umidade, bem como ao estresse causado nos mesmos ao separá-los e agrupá-los em subcolônias como o recomendado pela ASTM D - 3345 (ASTM, 2005b).

\section{CONCLUSÕES}

Os óleos de nim e de mamona, na retenção empregada, não contribuíram para a melhoria da resistência da madeira de sumaúma (Ceiba pentandra) ao ataque de cupins xilófagos. Dentre as soluções testadas, o óleo de mamona puro foi mais eficiente.

$\mathrm{O}$ envelhecimento das amostras (volatilização e lixiviação) não influenciou a resistência da madeira.

Cerne, Lavras, v. 16, n. 1, p. 105-113, jan./mar. 2010
Os óleos de nim e de mamona puros e as soluções preparadas com os mesmos não foram eficientes no tratamento da madeira, a fim de melhorar sua resistência a cupins xilófagos, pois embora tenham apresentado algum efeito de repelência, este não foi duradouro.

\section{AGRADECIMENTOS}

Ao Conselho Nacional de Desenvolvimento Científico e Tecnológico $(\mathrm{CNPq})$ pela concessão de Bolsa de Produtividade em Pesquisa (Processo 309461/2006-5) ao primeiro autor e de Iniciação Científica ao segundo autor.

\section{REFERÊNCIAS BIBLIOGRÁFICAS}

AMERICAN SOCIETY FOR TESTING AND MATERIALS. ASTM D-1413: standard test method for wood preservatives by laboratory soil-block cultures. Philadelphia, 2005a. 7 p.

AMERICAN SOCIETY FOR TESTING AND MATERIALS. ASTM D-3345: standard method for laboratory evaluation of wood and other cellulosic materials for resistance to termites. Philadelphia, 2005b. 3 p.

ARAÚJO, L. V. C.; RODRIGUEZ, L. C. E.; PAES, J. B. Características físico-químicas e energéticas da madeira de nim indiano. Scientia Forestalis, Piracicaba, n. 57, p. 153-159, 2000.

FONSÊCA, C. M. B. Eficiência do óleo de candeia (Eremanthus erythropappus (DC.) Macleish) na melhoria da resistência da madeira de sumaúma (Ceiba pentandra (L.) Gaertn) ao cupim xilófago Nasutitermes corniger Motsch. 2008. 22 f. Monografia (Graduação em Engenharia Florestal) Universidade Federal de Campina Grande, Patos, 2008.

HUNT, G. M.; GARRATT, G. A. Wood preservation. 3. ed. New York: Mc Graw Hill, 1967. 433 p.

JANKOWSKY, I. P. Potencialidade do creosoto de Eucalyptus spp, como preservativos para madeiras. 1986. 159 f. Tese (Doutorado em Engenharia) - Escola Politécnica, Universidade de São Paulo, São Paulo, 1986.

LEPAGE, E. S.; GERALDO, F. C.; ZONOTTO, P. A.; MILANO, S. Métodos de tratamento. In: LEPAGE, E. S. (Coord.). Manual de preservação de madeiras. São Paulo: IPT, 1986. v. 2, p. 343419. 
LOUREIRO, A. A.; SILVA, M. F.; ALENCAR, J. C. Essências madeireiras da Amazônia. Manaus: Instituto Nacional de Pesquisas da Amazônia, 1979. v. 2, 187 p.

MACHADO, C. C.; GARCIA, A. R.; SILVA, E.; SOUZA, A. P. Análise técnico-econômica do uso dos óleos de mamona (Ricinus communis, L.) e mineral como lubrificantes do conjunto de corte de motosseras. Revista Árvore, Viçosa, v. 22, n. 1, p. 123-134, 1998.

PAES, J. B. Efeitos da purificação e do enriquecimento do creosoto vegetal em suas propriedades preservativas. 1997. 143 f. Tese (Doutorado em Ciência Florestal) - Universidade Federal de Viçosa, Viçosa, 1997.

PAES, J. B.; LIMA, C. R.; MORAIS, V. M. Resistência natural de nove madeiras do semi-árido brasileiro a cupins subterrâneos, em ensaio de preferência alimentar. Brasil Florestal, Brasília, v. 20, n. 72, p. 59-69, 2001.

PAES, J. B.; MELO, R. R.; LIMA, C. R. Resistência natural de sete madeiras a fungos e cupins xilófagos em condições de laboratório. Cerne, Lavras, v. 13, n. 2, p. 160-169, 2007.

PAES, J. B.; MORAIS, V. M.; FARIAS SOBRINHO, D. W.; BAKKE, O. A. Resistência natural de nove madeiras do semiárido brasileiro a cupins subterrâneos, em ensaio de laboratório. Cerne, Lavras, v. 9, n. 1, p. 36-47, 2003.
PAES, J. B.; VITAL, B. R. Resistência natural da madeira de cinco espécies de eucalipto a cupins subterrâneos em teste de laboratório. Revista Árvore, Viçosa, v. 24, n. 1, p. 1-6, 2000.

PAES, J. B.; VITAL, B. R.; DELLA LUCIA, T. M. C.; DELLA LUCIA, R. M. Eficiência do creosoto vegetal contra cupins subterrâneos em testes de laboratório. Revista Árvore, Viçosa, v. 22, n. 1, p. 89-98, 1998.

PLANETANATURAL. Disponível em: <http:// 'WwW.planetanatural.com! br/ detalhe.asp?cod_secao $=14 \&$ idnot $=438$ - 35k ->. Acesso em: 29 jun. 2006.

RICHARDSON, B. A. Wood preservation. 2. ed. London: E \& FN SPON, 1993. 226 p.

SOUZA, M. H.; MAGLIANO, M. M.; CAMARGOS, J. A. A.; SOUZA, M. R. Madeiras tropicais brasileiras. Brasília: IBAMA/DITEC, 1997. $152 \mathrm{p}$.

STEEL, R. G. D.; TORRIE, J. H. Principles and procedures of statistic: a biometrical approach. 2. ed. New York: McGrawHill, 1980. 633 p.

SUPRIANA, N. Notes on the resistence of tropical wood against termites. Stockholm: The International Research Group on Wood Preservation, 1985. 9 p. (IRG/WP, 1249).

VENTURA, C. Mamona: lançada variedade mais produtiva. Revista Balde Branco, São Paulo, v. 26, n 304, p. 22-25, 1990. 